\title{
Application of the Flame-resisting Magnesium Alloy to Body Shell
}

\author{
Hisashi MORI \\ Naotaka UEHIGASHI \\ Toru MIYAUCHI \\ Frictional Materials Laboratory, Materials Technology Division
}

\begin{abstract}
Taro TSUJIMURA
Research and Development Promotion Division

Hiromichi ISHIDUKA

Vehicle Structure Technology Division

The use of high-strength flame-resistant magnesium alloy appears to be a promising route to reduce the weight of car body shells. Since research and development of flame-resistant magnesium alloy has just started, basic data and processing technologies still need to be investigated. This paper presents the results of investigations on its test processing, evaluation of its mechanical properties and workability. The trial manufacturing of hollow extruded materials and welding processes using this alloy are also briefly described.
\end{abstract}

Keywords: weight reduction, flame-resistant magnesium alloy, strength, hollow extruded materials, welding

\section{Introduction}

There are continuous calls to save more energy on Shinkansen trains. Technological solutions are one way to achieve this by cutting the weight of car body structures. It is thought that employing lighter materials to build car body structures can be an effective means to realize this goal. Accordingly aluminum based alloys have been used on Shinkansen trains to reduce car body weight [1] [2].

Nonetheless in an attempt to reduce car body weight even further, proposals to use flame-resistant magnesium alloys are now under examination. Flame-resistant magnesium alloy is a magnesium alloy which has had calcium added to it. Using flame-resistant magnesium alloy should make it possible to build higher car bodies. However, several properties of this material, such as its mechanical properties, workability and weldability, remain to be investigated before it can be applied in the construction of railway vehicle structures.

This paper first gives a brief overview of how lightweight materials are currently used in vehicle body structure. It then describes the evaluation of the prototype flame-resistance magnesium alloy, its microstructure characteristics, mechanical properties and workability, with a view to employing it for railway vehicles. Finally, the possibility of manufacturing hollow extruded materials using this flame-resistant magnesium alloy and its behavior when subject to welding and joining technology, were investigated.

\section{Lightening vehicles structure through use of flame-resistant magnesium alloy}

Steel has in the past been substituted with honeycomb aluminum based alloy panels and carbon fiber reinforced plastic (CFRP), to reduce vehicle body weight [2-4]. They are applied only to a part of the vehicle, and now aluminum alloy is applied widely to the vehicle [4].

In order to produce even lighter vehicle bodies, investigations need to be made in the future to replace the alumi- num alloy with magnesium alloy which is even lighter.

Considerable weight reduction should be achieved given the low density of the magnesium alloy and CFRP, however, application of magnesium alloy to vehicles body structures has never been tried before because magnesium alloy can generate a certain chemical activity which is potentially easily flammable. If magnesium alloy is to be applied in practice therefore it is critical to ensure that it is made flame resistant. One known effective method to create flame resistance is to add calcium to a magnesium alloy (hereafter in this report referred to as flame-resistant magnesium alloy) [5]. A prototype flame-resistant magnesium alloy has already been manufactured, but its properties are not clear, and it has thus never reached the stages of being put to practical use. Basic tests were performed to determine its properties therefore in order to make it applicable to the vehicle body structures featured in this report.

\section{Content of the experiment}

When employing new materials on a vehicle body structure it is necessary to understand their mechanical properties and establish a manufacturing process. In addition, material shaping, and welding and joining technologies required for the assembling of the vehicle must be also tried and tested. The items tested in the experiment are summarized in Table 1.

\section{Results and discussion}

\subsection{Trial production and evaluation of microstruc- ture}

\subsubsection{Alloy development}

Generally in the case of magnesium alloy design, zinc and aluminum are added to improve casting and strength, respectively. For this research a prototype flame-resistant magnesium alloy was produced adding zinc, aluminum 
Table 1 Experimental items

\begin{tabular}{|c|c|c|}
\hline Items & Research target & Content of examination \\
\hline \multirow{2}{*}{$\begin{array}{l}\text { Trial production of } \\
\text { materials and } \\
\text { evaluation of } \\
\text { microstructure }\end{array}$} & $\begin{array}{l}\text { Lessening defect in production } \\
\text { technique }\end{array}$ & $\begin{array}{l}\text { Trial production with casting process } \\
\text { under various atmosphere }\end{array}$ \\
\hline & $\begin{array}{l}\text { Homogenizing of } \\
\text { metallographic structure }\end{array}$ & $\begin{array}{l}\text { Observation and chemical analysis of } \\
\text { microstructure }\end{array}$ \\
\hline $\begin{array}{l}\text { Evaluation of flame } \\
\text { resistance, mechanical } \\
\text { properties and } \\
\text { workability }\end{array}$ & $\begin{array}{l}\text { Obtaining various } \\
\text { characteristics on aluminum } \\
\text { alloy level }\end{array}$ & $\begin{array}{l}\text { Investigation of flame resistance, } \\
\text { mechanical properties (strength and } \\
\text { expansion), and workability } \\
\text { (high-temperature ductility and rolling } \\
\text { ductility) }\end{array}$ \\
\hline $\begin{array}{l}\text { Trial manufacture of } \\
\text { the hollow shape } \\
\text { samples }\end{array}$ & $\begin{array}{l}\text { Confirmation of the possibility } \\
\text { of trial manufacture with } \\
\text { highly precise shape }\end{array}$ & $\begin{array}{l}\text { Evaluation of the trial manufacture of } \\
\text { the model hollow shape using } \\
\text { extrusion technique and precision } \\
\text { sizing }\end{array}$ \\
\hline $\begin{array}{l}\text { Evaluation of the } \\
\text { welding and joining } \\
\text { method }\end{array}$ & $\begin{array}{l}\text { Confirmation of the possibility } \\
\text { of welding and joining, and } \\
\text { condition of the welded and } \\
\text { joint parts }\end{array}$ & $\begin{array}{l}\text { Examination of joining characterized } \\
\text { by TIG arc welding and by the friction } \\
\text { stir welding (FSW) and evaluation of } \\
\text { the microstructure of welded and } \\
\text { joined part }\end{array}$ \\
\hline
\end{tabular}

and calcium. The casting atmosphere strongly influences the production of the magnesium alloy. Therefore after the alloy was dissolved at high temperature, it was cast both in open air and in a vacuum. After casting, its microstructure was inspected through an optical microscope. Figure 1 shows the microstructure of alloy AZX611 cast in the open air (a) and in a vacuum (b). Alloy AZX611 is an alloy of Mg$6 \mathrm{Al}-\mathrm{Zn}-\mathrm{Ca}$ with $6 \%$ aluminum, $1 \%$ zinc and $1 \%$ calcium added to the magnesium. A void was generated by casting in the open air. A good microstructure without defects was obtained however when cast in a vacuum.

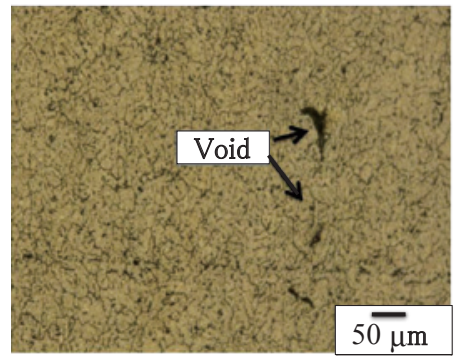

(a) Open air casting

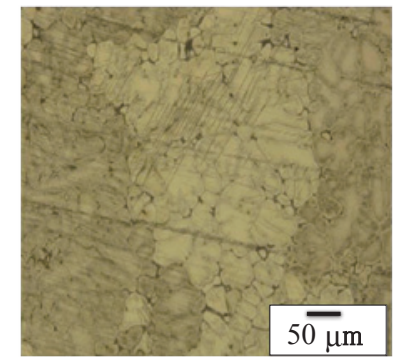

(b) Vacuum casting
Fig. 1 Microstructure produced by changing the casting atmosphere for alloy AZX611

\subsubsection{Characterization of microstructures}

Precipitation and grains were shown in microstructure of the aluminum alloy. However, no standard microstructure has to date been identified for flame-resistant magnesium alloy. Figure 2 shows optical micrograph of the alloy AZX611 (rolled material) microstructure which is an alloy of Mg-6Al-Zn-Ca with a composition of 6\% aluminum, $1 \%$ zinc and $1 \%$ calcium added to the magnesium. It was observed that precipitated materials were nucleated within crystal grains and along crystal grain boundaries. This type of microstructure suggests that the alloy must be strong. In order to examine the composition of precipitation and chemical composition, transmission electron microscope (TEM) and energy dispersion spectrometry (EDS) were used.

The microstructure observed through TEM imaging

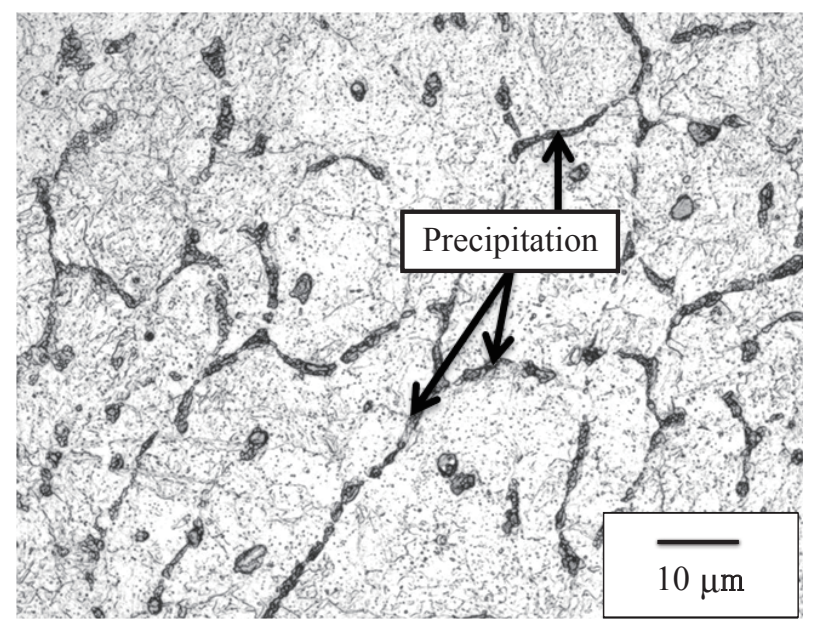

Fig. 2 Microstructure of alloy AZX611 (rolled material) 


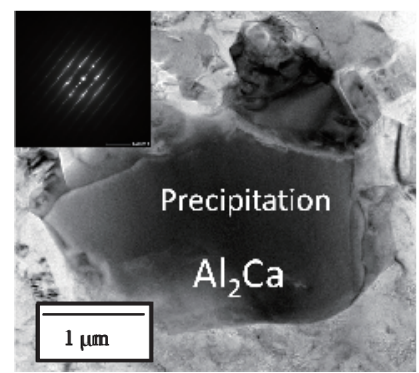

(a) Precipitation

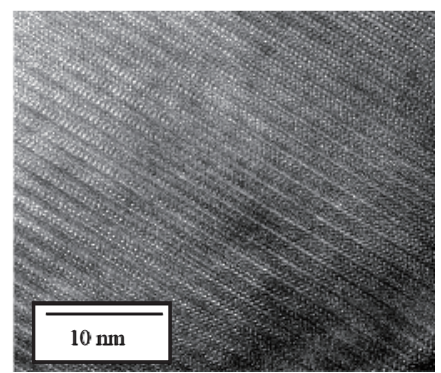

(b) Atomic image of precipitation
Fig. 3 Microstructure by TEM observation

and the deflection pattern are shown in Fig.3. A majority of size of precipitation was less than $10 \mu \mathrm{m}$ and the precipitation comprised regular atom sequences as shown in Fig. 3(b). According to analysis by TEM and EDS, it is thought that this precipitation is a compound of aluminum and calcium. In addition, it was confirmed that the precipitation in extruded material has a microstructure similar to that of rolled materials.

\subsection{Evaluation of flame resistance, mechanical prop- erties and workability}

\subsubsection{Evaluation of flame resistance}

A prototype flame-resistant magnesium alloy was manufactured and its flame resistance was evaluated. There are no quantitative methods for evaluating flame resistance at present. In this evaluation therefore, the specimens were heated directly with a gas burner, and their temperature was measured with a thermocouple. Flame resistance was then evaluated by observing at what temperature the materials ignited. In order to examine the influence of adding calcium on flame resistance, both the alloy AZX611 and materials with no added calcium (Mg-6Al-Zn: alloy AZ61) were used. In addition, 6000 series aluminum alloy (alloy 6N01) was used to compare the tested materials and the aluminum alloy. Figure 4 shows the experimental set up. Alloy AZ61 to which no calcium had been added ignited at $700 \mathrm{~K}$, whereas 6N01 and alloy AZX611 with added calcium simply melted at this temperature without catching fire.

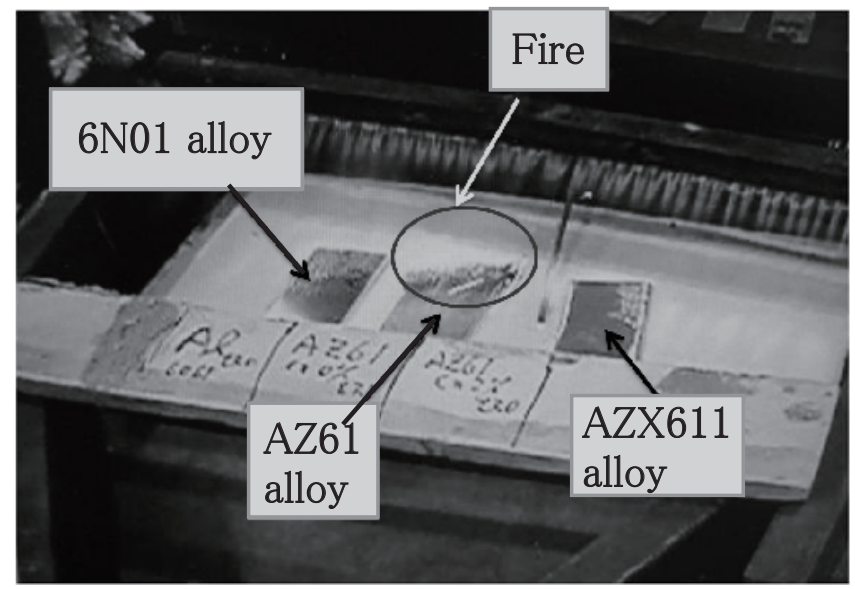

Fig. 4 Examination of flame resistant properties
These results confirmed that the flame resistant properties of alloy AZX611 were equivalent to those of alloy $6 \mathrm{~N} 01$, and further confirmed that the flame resistance magnesium alloy could be improved by adding calcium. Improvement of flame resistance by adding calcium is thought to be achieved because of the formation of an oxidation film which intercepts oxygen. However, gaining clearer insight into this mechanism is a task for the future.

\subsubsection{Evaluation of mechanical property}

The strength of flame-resistant magnesium alloy is considered to be influenced by the aluminum content. Proof stress, tensile stress and elongation of flame-resistant magnesium alloy were evaluated by adjusting the aluminum content to 3, 6 and $9 \%$. In these tests $\mathrm{Ca}$ and $\mathrm{Zn}$ content each represented $1 \%$. The size of tensile specimen was determined according to Japan Industrial Standard (JIS) on 14 proportion size of specimen. Tensile tests were performed on an Instron type tensile machine and the tests were conducted at ambient room temperature. The results of the proof stress, tensile stress and elongation tests are shown in Table 2. Confirmation was obtained that the proof stress of flame-resistant magnesium alloys AZX611 and AZX911 (with 9\% aluminum, 1\% zinc and 1\% calcium), was greater than the minimum value obtained for alloy $6 \mathrm{~N} 01$.

Table 2 Proof stress, tensile stress and elongation of flame-resistant magnesium alloy

\begin{tabular}{|c|c|c|c|}
\hline Alloy & $\begin{array}{c}0.2 \% \text { proof stress } \\
(\mathrm{MPa})\end{array}$ & $\begin{array}{c}\text { Tensile fracture stress } \\
(\mathrm{MPa})\end{array}$ & Elongation (\%) \\
\hline $\begin{array}{c}\text { Mg-3Al-Zn-Ca } \\
\text { (AZX311 alloy) }\end{array}$ & 230 & 255 & 16 \\
\hline $\begin{array}{c}\text { Mg-6Al-Zn-Ca } \\
\text { (AZX611 alloy) }\end{array}$ & 270 & 285 & 15 \\
\hline $\begin{array}{c}\text { Mg-9Al-Zn-Ca } \\
\text { (AZX911 alloy) }\end{array}$ & 260 & 270 & 7 \\
\hline 6N01 (JIS) & $>250$ & - & $>20$ \\
\hline
\end{tabular}

\subsubsection{Evaluation of workability}

Flame-resistant magnesium alloy has a crystal structure which makes processing difficult. Consequently this means processing at room temperature is a problem. Temperature and processing speed therefore need to be modified. The influence of temperature and strain rate on elongation and strength of the flame-resistant magnesium alloy was examined through tests. Figure 5 shows the relationship between elongation and the strain rate depending on the test temperature used on alloy AZX611. Increasing the temperature, and lowering the strain rate, increases elongation. At temperatures over $573 \mathrm{~K}$ in particular, elongation exceeded $100 \%$ at the low strain rate of $10^{-4} \mathrm{~s}^{-1}$.

Generally, processing speeds selected for processes on the new material, such as rolling and extrusion, were 


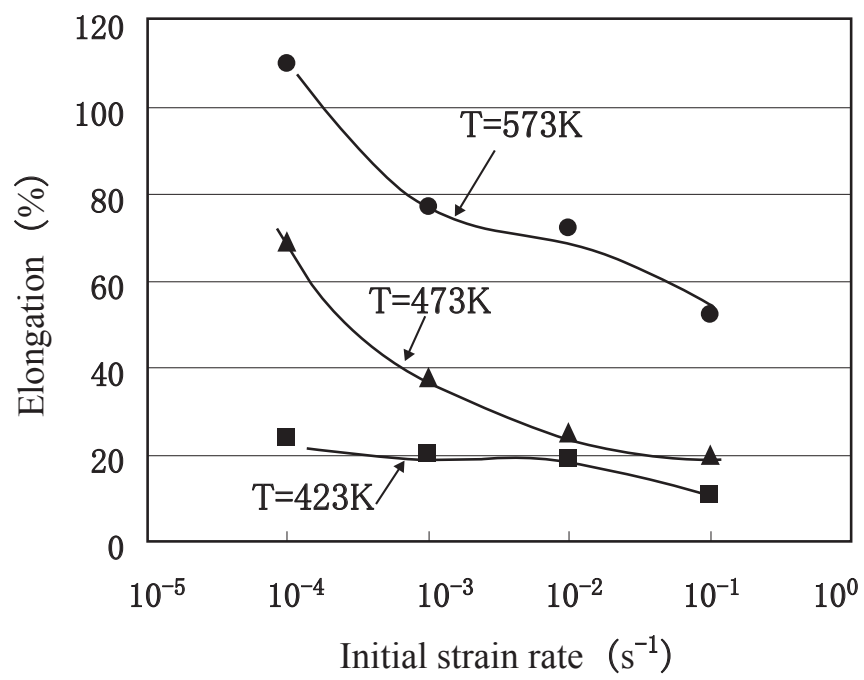

Fig. 5 Relationship between elongation and strain rate of AZX611 alloy

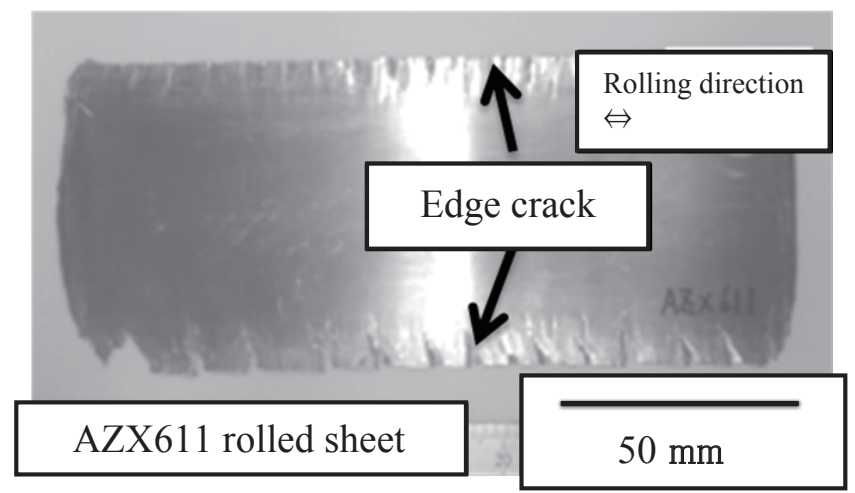

Fig. 6 Typical example of the AZX611 alloy sample rolled at $373 \mathrm{~K}$

\section{(R.D. : Rolling direction)}

higher than the strain rate shown in Fig.5 [5]. Therefore evaluation of workability was estimated using materials processed by the real rolling method. A typical example of alloy AZX611 rolled at $373 \mathrm{~K}$ is shown in Fig. 6. The edge crack was generated when rolling at $373 \mathrm{~K}$. On the other hand, there were no cracks when the heating temperature was increased to $573 \mathrm{~K}$. This result confirms that it is difficult to process flame-resistant magnesium alloy at room temperature, contrary to aluminum base alloys, however, its increases with heating.

\subsection{Trial manufacture of hollow shaped samples}

When aluminum base alloy is applied to a vehicle body structure, the coefficient of elasticity of aluminum alloy is lower than that of steel, which means that the necessary rigidity cannot be obtained. This is the reason why hollow shaped materials have come to be used [1]. The coefficient of elasticity of the flame-resistant magnesium alloy is almost the same as that of a general magnesium alloy and is lower than that of aluminum alloy. Therefore, its rigidity must be examined. Accordingly, a hollow shaped sample was processed experimentally in order to confirm whether hollow shaped flame resistant magnesium alloy could be

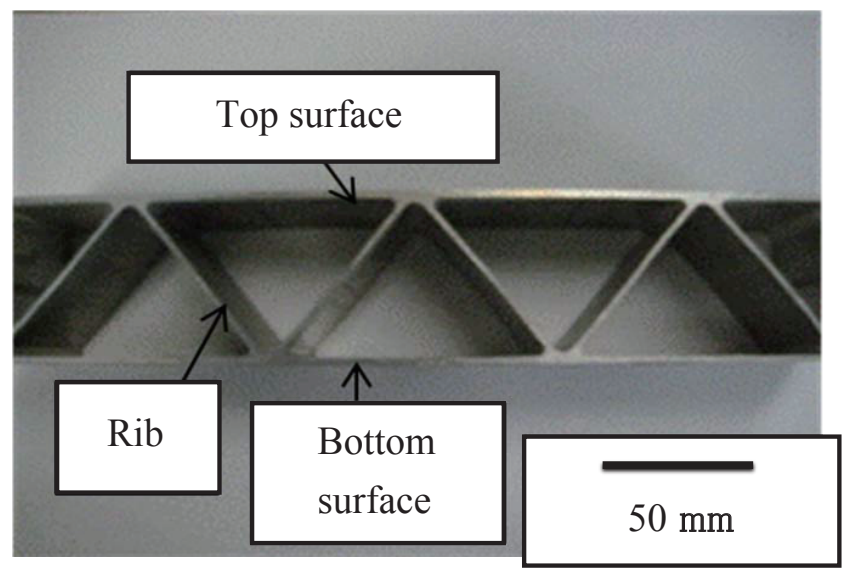

Fig. 7 Typical example of model samples of hollow shaped material made with AZX611 alloy

manufactured and produced to the required precise dimensions.

A model shape sample was produced by extrusion method for this study. The dimensions of model sample were set to: width of $250 \mathrm{~mm}$, length of $5 \mathrm{~m}$, height of 50 $\mathrm{mm}$, thickness of the rib of $1.5 \mathrm{~mm}$, and thickness of top plate and bottom plate of $2.0 \mathrm{~mm}$. Figure 7 shows the hollow shape model sample made with the AZX611 alloy. It is thought that the hollow sample of dimensions almost the target was produced, though the generation of seizure of the face sheet was sometimes observed when processing it. It was confirmed for the first time that hollow shaped models employing magnesium alloys could be manufactured, though some problems remain with respect to the number of experimental models and the accuracy of measurements. It is scheduled that the shape and the size of the hollow shape modes made of the flame-resistant magnesium alloy are to be reviewed, and trial manufacture of long models with high accuracy will be examined in the future.

\subsection{Evaluation of the welding and joining method}

Examination of the welding and joining techniques was necessary to ensure that flame-resistant magnesium alloy can be applied to railway vehicles. Friction stir welding (FSW) is used in production and TIG arc welding is used for repairing aluminum alloy on railway vehicle bodies. Therefore, tests were performed to evaluate the application of TIG arc welding and the FSW to flame-resistant magnesium alloy.

\subsubsection{Application of TIG arc welding}

TIG arc welding was applied to AZX311 and AZX611 alloys under the same conditions used in the case of aluminum alloy. In TIG arc welding, a TIG rod of $\varphi 2.7 \mathrm{~mm}$ produced from AZX611 alloy was used. Figure 8 shows the outline of the welded parts. No defect was observed on the surface in this test. The results of macroscopic observation of the cross-section of the welded parts of AZX311 alloy and AZX611 alloy are shown in Fig. 9.

No defects were observed in the cross sections. It was confirmed that TIG arc welding of flame-resistant magnesium alloy could be welded under the same conditions 


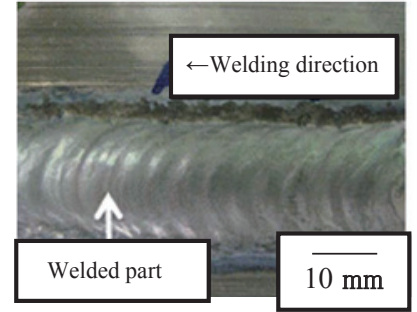

(a) AZX311 alloy

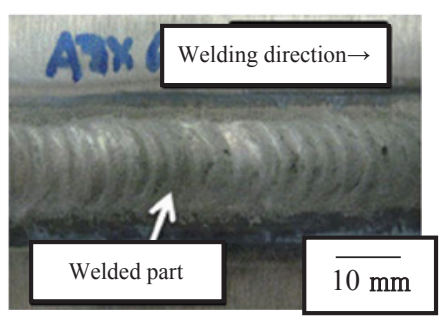

(b) AZX611 alloy
Fig. 8 Observation of TIG welded parts

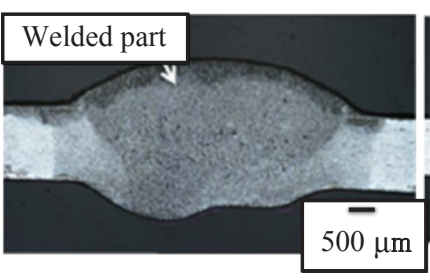

(a) AZX311 alloy

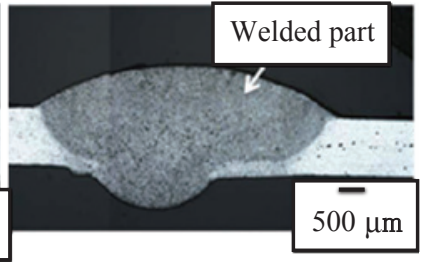

(b) AZX611 alloy
Fig. 9 Macroscopic observation of the cross-section of the welded parts

applied for aluminum alloy. According to the tensile test of the welding sample, joint efficiency (tensile stress of joined sample / tensile stress of base material) was $75 \%-80 \%$ of the parent metal.

\subsubsection{Application of FSW}

In late years, FSW has attracted attention and been used for the production of railway vehicle bodies made with aluminum alloy [6]. Welding tests were performed therefore on flame-resistant magnesium alloy using FSW under the same conditions applied to aluminum alloy. Figure 10

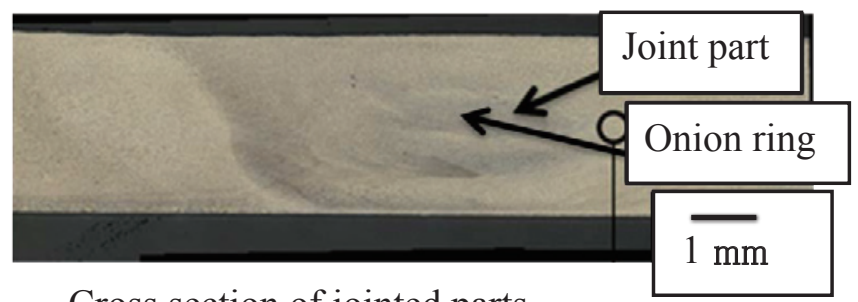

Cross section of jointed parts

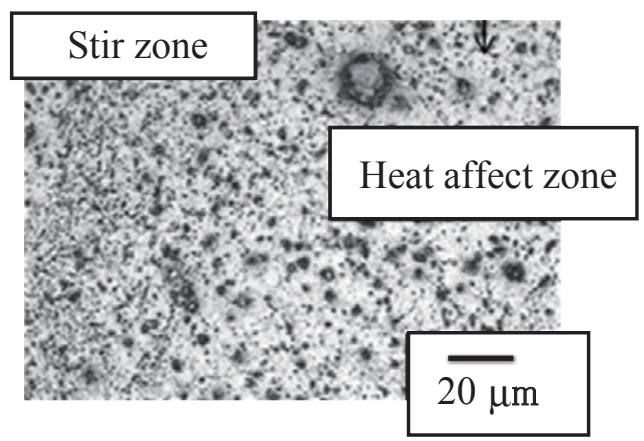

Boundary of stir zone and heat affect zone

Fig. 10 Microstructure of jointed part of AZX611 alloy by FSW shows the typical cross sectional microstructures at the joints with AZX611 alloy after FSW. Circular patterns can be seen on the joins. It has been reported that this type of "onion ring" circular pattern is a typical indication of microstructural change during FSW [7]. Detailed observation revealed that the microstructure in the stir zone and in the heat-affected zone differed in size scale of grains. Tensile tests of join samples revealed a join efficiency of $92 \%-98 \%$ of the parent metal. It is thought that a higher joint efficiency can be obtained with FSW than with TIG arc welding.

\section{Conclusions}

In order to reduce the weight of railway vehicles, a new flame-resistant magnesium alloy was developed. This study describes tests performed to evaluate methods for processing this material, its microstructure, mechanical properties, workability and possibility of using it to manufacture hollow extruded samples and other trials carried out to examine its applicability in welding and joining methods. The results of the research are summarized as follows:

(1) It is possible to manufacture flame-resistant magnesium alloy without defects if cast in a vacuum.

(2) Tests confirmed that the strength of flame-resistant magnesium alloy is the same as that of an aluminum (6N01) alloy, and that its workability can be ensured by processing it at the appropriate temperature.

(3) It was possible that hollow shaped model samples of flame-resistant magnesium alloy could be produced experimentally and precisely by extrusion method.

(4) Both TIG arc welding and FSW can be applied to the welding of flame-resistant magnesium alloy, although FSW has a higher joint efficiency than TIG arc welding.

\section{Acknowledgments}

The authors would like to express their sincere gratitude to Mr. Satoru Hanaki and Mr. Kazunori Shimizu (Sankyo Material-Company co. ltd.), Prof. Kunio Funami and Dr. Masafumi Noda (Chiba Institute of Technology), Dr. Takeshi Ishikawa (Japan Transport Engineering Company) and Dr. Eitaro Yukitake (Industrial Technology Institute of Ibaraki Prefecture) for their guidance and teaching.

\section{References}

[1] Suzuki, Y., "Lightening railway vehicle with aluminum base alloy, future tasks," Journal of Japan Institute of Light Metals, Vol. 60, No. 11, pp.565-570, 2010 (in Japanese).

[2] Mizuta, A. and Kimura, T., "Material characterization of light metal that railway vehicle requests," Material, Vol. 43, No. 5, pp.392-395, 2004 (in Japanese).

[3] Suzuki, Y., "Current state and the future of composite materials use in vehicle field," Journal of Japan Welding Society, Vol. 64, No. 8, pp.612-614, 1995 (in Japa- 
nese).

[4] Mori, H. and Tsujimura, T., "Transition of material technology for vehicle,” RRR, Vol. 67, No. 3, pp.8-11, 2010 (in Japanese).

[5] Akiyama, S. and Ueno, T. et al., "Development of flame resistance magnesium alloy," Material, Vol. 39, No. 1, pp.72-74, 2000 (in Japanese).
[6] Okamura, H., Aomura, K. et al., "Development situation of friction stir joint (FSW) and problem in application," Journal of Japan Welding Society, Vol. 72, No. 5, pp.436-439, 2003 (in Japanese).

[7] Shibayanagi, T., "Material texture academic of friction stir joint," Journal of Japan Institute of Light Metals, Vol. 57, No. 9, pp.416-423, 2007 (in Japanese).

\section{Authors}

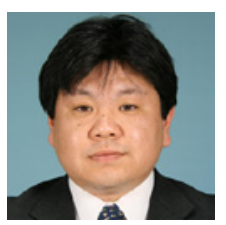

Hisashi MORI, Dr. Eng.

Senior researcher, Frictional Materials

Laboratory, Materials Technology Division

Research Areas: Alloy design and processing,

fracture mechanics

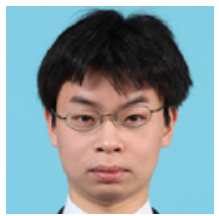

Naotaka UEHIGASHI

Researcher, Frictional Materials Laboratory,

Materials Technology Division

Research Areas: Light weight material

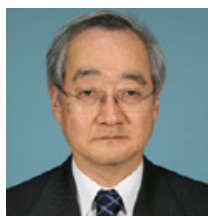

Taro TSUJIMURA, Dr. Eng.

Principal Researcher, Research and Development Promotion Division Research Areas: New materials, Brake materials and LCA

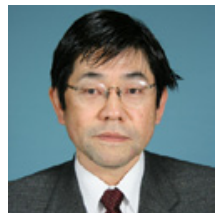

Hiromichi ISHIDUKA

Principal Researcher, Vehicle Structure Technology Division

Research Areas: Structural and fracture evaluation, Metallic materials

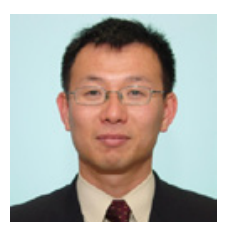

Toru MIYAUCHI, Dr. Eng.

Laboratory Head, Frictional Materials

Laboratory, Materials Technology Division

Research Areas: Brake material and tribology 